\title{
HISTÓRIA E LITERATURA: OS ESCRITOS COLONIAIS DE FINS DO SÉCULO XVI E IN ÍCIO DO XVII *
}

\author{
Claudine Magno MagreMendes ${ }^{* *}$
}

Resumo. Neste artigo analisamos a obra de Pero de Magalhães Gândavo no interior do que denominamos escitos coniais. São textos escritos entre as últimas décadas do século XVI e as primeiras do XVII. A intenção de Gândavo, assim como a dos demais autores coloniais, é defender os interesses dos colonos. Com isso, contrariamos a historiografia em geral e a historiografia da literatura brasileira em particular, que os veem como autores identificados com os interesses metropolitanos.

Palavras-chave: Gândavo; Colonização; Escritos coloniais; Interesses coloniais.

\section{HISTORY AND LITERATURE: THE COLONIAL WRITINGS OF THE LATE $16^{\text {TH }}$ AN D EARLY $17^{\text {TH }}$ CENTURY}

\begin{abstract}
In this article, we analyze the works of Pero de Magalhães Gândavo in what we name codoial writings They are texts written between the late $16^{\text {th }}$ century and the early 17th century. Gândavo's intention, as with the other colonial writers, is to defend the interests of the settlers. With that, we counter historiography in general and Brazilian historiography in particular, which sees them as authors identified with metropolitan interests.
\end{abstract}

Keywords: Gândavo; Colonization; Colonial writings; Colonial interests.

\section{HISTORIA Y LITERATURA: LOS ESCRITOS COLONIALES DE FINES DEL SIGLO XVI Y COMIENZOS DEL XVII}

Resumen. En este artículo analizamos la obra de Pero de Magalhães Gândavo en el contexto de lo que llamamos escritos coniales Son textos escritos entre las

* Artigo recebido em 30 de outubro de 2009 e aprovado em 17 de novembro de 2009.

** Professor do Programa de Pós-G raduação em História da Unesp/ Assis. Este artigo foi baseado na tese de doutorado Construindo umnovo munda Os escritos coloniais do Brasil nos séculos XVI e XVII. São Paulo: FFLCH/ USP, 1996. 
últimas décadas del siglo XVI y las primeras del XVII. La intención de Gândavo, como así también de los demás autores coloniales, es defender los intereses de los colonos. Con ello, contrariamos la historiografía en general y la historiografía de la literatura brasileña en particular que ven a estos autores identificados con los intereses metropolitanos.

Palabras Clave: Gândavo; Colonización; Escritos coloniales; Intereses coloniales.

E como o lugar das grandes vitórias costuma sempre descreverse, para maior clareza delas; eu, que desejo declarar estas nossas com toda a inteireza possível, seguirei o estilo comum: mormente sendo o campo destas um Mundo novo, ainda em 0 tempo presente mal conhecido, quanto mais no daquelas empresas primeiras; é força, não já de estilo somente, mas de necessidade, que descreva primeiro este lugar, onde as batalhas foram por uma parte tão feridas, e por outra tão remontadas dos olhos dos homens, que pedem para crédito seu toda a distinção, e clareza. Nem será razão por outra via, que aqueles que hão de entrar em um tão forte desafio, partam sem saber 0 lugar, onde há de ser o conflito; e passem de um mundo a outro mundo, sem que tenham primeiro notícias dele; que região é, quando e como foi descoberta, quais sejam suas qualidades, seus climas, suas gentes, seus costumes. E suposto que andem já algumas destas notícias em outros escritos, é acaso, ou por curiosidade: aqui vem por obrigação da História (Simão de Vasconcelos, Crônica da Companhia deJesus 1663).

\section{INTRODUÇÃO}

Para tratar da relação entre história e literatura é necessário explicitar alguns aspectos da questão da consciência, já que a arte constitui uma de suas manifestações. Embora não caiba, neste texto, examinar todas as formulações a respeito dessa questão, devemos, para os nossos propósitos, chamar a atenção para duas questões.

A primeira diz respeito às maneiras básicas de se compreender a relação entre a práxis e a consciência. Na primeira, a consciência aparece como uma espécie de reflexo das condições materiais de existência do homem, isto é, das suas relações de produção. Os que se apoiam nesta forma de pensar acreditam que o estudo dessas condições materiais e de sua evolução seria suficiente para dar conta da história. Na segunda, a consciência aparece como autônoma em relação a essas condições, razão 
pela qual se acredita ser possível fazer uma história da consciência. Seja com 0 nome de história das ideias, seja com 0 de história das mentalidades ou de história intelectual, a consciência é abordada como se fosse desligada das condições materiais. Ambas as perspectivas têm em comum enfatizar apenas um aspecto da vida social dos homens. Com efeito, enquanto uma salienta 0 aspecto material, a outra acentua 0 espiritual. $\mathrm{O}$ resultado é que cada uma apreende o fenômeno histórico de maneira parcial, unilateral.

Entendemos que não se pode compreender o processo histórico senão com base em sua totalidade, considerando-se tanto as condições de existência dos homens quanto sua consciência. Os homens não fazem a história sem uma base material e sem uma explicação do universo social em que vivem. Seria impensável, por exemplo, a Revolução Francesa sem a Fisiocracia e o Iluminismo, formas da consciência pelas quais os franceses tomaram conhecimento das questões de sua época e explicaram o mundo em que viviam. Mais do que isso, uma e outro constituíram uma espécie de diretriz para a ação dos franceses de então.

A segunda questão refere-se ao fato de que as formas da consciência variam. Ela pode assumir a forma religiosa, a filosófica, a econômica, a política, a artística ou literária, e assim por diante. Assim, é preciso considerar a especificidade dessas formas de consciência para poder valer-se delas para o estudo e a compreensão de determinado processo histórico.

Enfim, entendemos ser necessário abandonar as formulações simplistas, que consideram, em determinadas circunstâncias, a consciência - geralmente sob o termo ideologia - como um instrumento de escamoteação da "realidade" e de dominação social e política. Nessa perspectiva, a consciência é vista como "desligada" das condições sociais de existência e manipulável ao sabor da vontade dos grupos dominantes, por exemplo.

De nosso ponto de vista, a consciência deve ser entendida como parte integrante da totalidade social e, por isso mesmo, indissociável desse todo.

Esta maneira de considerar a consciência é distinta das formas anteriormente mencionadas em vários aspectos. Em primeiro lugar, não entendemos a consciência como algo passivo, mero reflexo das condições materiais de existência. Em segundo lugar, não compreendemos a consciência como algo desvinculado das condições de existência dos homens. De nosso ponto de vista, as diferentes formas de consciência 
são exatamente isso, ou seja, maneiras pelas quais os homens se inteiram de suas relações e das questões que se colocam para eles.

Não obstante, elas não são apenas meios pelos quais os homens tomam consciência das suas questões, já que a consciência também dirige sua prática, suas ações. Em última análise, as ideias "comandam" as ações dos homens. Considerada a questão a partir deste ângulo, a impressão que se tem é de que os homens são movidos pelas ideias, mas isso somente para aqueles que não levam em conta que estas nascem das próprias condições de existência dos homens. Deste último ponto de vista, concede-se à consciência um papel ativo, mas não autônomo, ou seja, ela é fundada nas condições materiais e a elas se dirige em última instância.

A literatura constitui uma forma específica de consciência: é regida por uma estética, por regras que comandam sua elaboração. Evidentemente, a própria estética é uma resposta às condições ou circunstâncias históricas. Além disso, diferentemente de um texto científico, o literário vale-se da criação aleatória, da intuição, da emoção, e assim por diante. Podemos dizer que um texto literário, ainda que se refira, em última análise, às condições materiais da época, fá-lo de maneira mediatizada, o que, de modo geral, torna essa referência não perceptível à primeira vista. Antes, a criação literária aparece frequentemente como "desligada" das condições gerais da sociedade.

Os textos que estudaremos podem ser considerados como literários apenas no sentido mais amplo da palavra. Foram, inclusive, objeto de estudos por parte dos historiadores da literatura brasileira, sendo caracterizados como "crônicas", "literatura de informação" e assim por diante. Foram, igualmente, utilizados pelos historiadores, se bem que, na maior parte das vezes, como repositórios de informações e dados. Somente muito recentemente eles se tornaram, também, objeto de estudos. São textos que, elaborados em finais do século XVI e início do XVII, trataram, basicamente, da Colônia, possuindo determinadas características que lhes são próprias. Com efeito, entre 1570 e 1630, grosso modo, encontramos alguns autores que trataram do Brasil em obras que se distinguem das cartas, das informações e das descrições elaboradas pelos colonos e pelos jesuítas até então. São eles Pero de Magalhães Gândavo (1965; 1980), Gabriel Soares de Sousa (1971), Ambrósio Fernandes Brandão, suposto autor dos Diálogos das Grandezas do Brasil (MELLO , 1966), e frei Vicente do Salvador (1982). 
Ainda que não sejam propriamente textos literários, entendemos que a reflexão anteriormente feita acerca da relação entre história e arte lhes é apropriada. Com efeito, a questão central é o modo como entendemos a relação entre a práxis social e a consciência. A partir de então, o problema da análise destes escritos é apreender a questão que se colocava aos portugueses do Reino e da Colônia.

\section{OS E SCRIT OS COLO NIAIS}

A literatura relativa ao Brasil, produzida entre as últimas décadas do século XVI e as primeiras do XVII, apesar da variedade quanto ao gênero (tratados, diálogos, história), possui determinadas características que lhe conferem certa unidade. 0 que unifica essas produções não são as características habitualmente a elas atribuídas pelos estudiosos da literatura, quando, por exemplo, classificam-nas como obras de informação e louvor à Colônia (BO SI, 1970, p. 15; 29). Em certo sentido, atendo-se aos seus aspectos mais aparentes, é possível concordar com semelhante classificação, mas isso não é suficiente para explicar o que as unifica. É preciso verificar o queesta literatura informava, queminformava e, finalmente, comquefinalidadeinformava (TUCK, 1992, p. 275).

Para seus estudiosos, presos a uma visão dualista e negativa da colonização, consubstanciada na ideia de que a metrópole explorava a colônia, estas obras informavam com o evidente propósito colonialista de atender aos interesses da Metrópole. Nestes estudos encontramos, com efeito, expressões como: "informava-se com objetivos marcadamente coloniais: explorar as potencialidades econômicas da terra em proveito do capital mercantil", "informava-se os poderes da Metrópole sobre as perspectivas que a Colônia oferecia", "informações sobre a terra para facilitar a exploração colonialista", "louvava-se a terra para glória da Metrópole", "para valorizar a terra aos olhos dos mercadores europeus" (ABDALA JR.; CAMPED ELLI, 1985, p. 10; BOSI, 1970, p. 18; 21).

Para nós, estes autores quinhentistas e seiscentistas não trataram a Colônia de uma suposta perspectiva metropolitana, sempre desejosa de explorar a nova terra descoberta. Eles informavam e louvavam a terra da perspectiva da própria colonização, isto é, da criação de novas relações sociais, cuja essência era a produção da riqueza. Posicionaram-se claramente a favor da colonização, colocaram-se de maneira inequívoca ao lado dos seus interesses. Seus escritos encontravam-se subordinados à intenção de expandir e fortalecer a colonização, ou seja, expandir e fortalecer a sociedade que se formava na Colônia. Em suma, seu intuito 
não era favorecer o Reino em detrimento da Colônia, e sim, favorecer a nascente sociedade. Exaltava-se a terra não com o objetivo de promover sua exploração, como afirma a historiografia, mas de estimular sua ocupação produtiva.

É esta conduta de defesa da colonização que confere certa unidade a essa literatura, constituindo, provavelmente, a mais importante de suas características. Neste sentido, as diferentes obras desse período estão unificadas pela defesa da Colônia como expressão das forças sociais emergentes. Por essa razão, podemos considerar seus autores como porta-vozes dos interesses que haviam sido criados com a colonização.

A afirmação de que esta literatura era a expressão de interesses originados da colonização pode causar certa estranheza. Afinal, vai contra o que comumente os historiadores e estudiosos da nossa literatura têm afirmado a seu respeito. Com efeito, de acordo com esses estudiosos, os escritos dos quinhentos e dos seiscentos acerca do Brasil não passariam de um prolongamento da literatura portuguesa, modificada, é verdade, pelas novas condições, inclusive as naturais (CASTELLO, 1969; CÂNDID O, 1982). Consequentemente, seus autores pertenceriam à tradição literária de Portugal. Assim, Não é casual que estejam presentes nas histórias da literatura portuguesa ou apareçam como apêndice da literatura portuguesa que trata de temas coloniais. Em um caso como no outro, são considerados portugueses que expressavam os interesses do Reino ou da Metrópole. Em decorrência disso, teriam criado uma literatura portadora da ideologia colonialista. Seus autores seriam ideólogos do colonialismo a serviço do bempartuguess (KO SHIBA, I, 1988, p. 171).

A principal razão de os estudiosos da história da literatura e os historiadores em geral conceberem a literatura dos primeiros séculos como uma literatura identificada com a Metrópole é, fundamentalmente, sua concepção de colonização. Para estes, a colonização encontra-se sempre associada às ideias de exploração colonial, dependência, subordinação aos interesses metropolitanos. Na raiz desta concepção encontramos a ideia de que existiria uma oposição de interesses entre metrópole e colônia e, assim, de que a produção colonial visaria atender a interesses estranhos à colônia. Bosi (1970, p. 13), por exemplo, define a colônia como algo distinto da metrópole, como o "outro" em relação à metrópole.

Ressalte-se, inclusive, que esta concepção de história se encontra tão entranhada nos estudos literários que, geralmente, os historiadores da literatura traçam um paralelo entre a história e a evolução literária no 
Brasil. Da mesma maneira que a história do Brasil evoluiria de colônia para nação, a literatura brasileira superaria as características coloniais para assumir feições nacionais (CASTELLO, 1969, p. 11); ou seja, marcharia no sentido do autodomínio, da mesma forma que 0 Brasil se encaminharia para a autossustentação. Não é casual que, semelhantemente a Caio Prado, que considerou o Brasil como uma nação em formação (PRAD O JR., 1981), os historiadores da literatura, como Afrânio Coutinho (1956), tenham afirmado que a independência literária era um processo em andamento.

Quanto a nós, evitando a oposição colônia-nação, fundamento da oposição colônia-metrópole, podemos afirmar que o fato de os autores coloniais tomarem partido da colonização não implica que sejam ideólogos dos interesses metropolitanos, partidários dos interesses metropolitanos, opostos aos da colônia. Na verdade, a historiografia costuma se portar como os mercantilistas, para quem as vantagens comerciais de uma nação somente poderiam existir em detrimento de outra. A historiografia não pode compreender que o bem do Reino interessava, e muito, aos colonos. Além disso, diga-se de passagem, estes não eram da opinião de que seus interesses se opunham aos da Metrópole.

A compreensão da colonização como uma maneira particular de constituição da moderna sociedade conduz à formulação de que os autores coloniais não devem ser encarados da perspectiva da oposição entre metrópole e colônia, e sim, do conflito entre duas épocas históricas. Igualmente, a afirmação de que estes autores eram a expressão das novas forças corporificadas na colonização não significa que os consideremos como uma espécie de protonacionalistas, cuja defesa dos interesses coloniais corresponderia a um posicionamento contra a metrópole, a um precoce sentimento nativista (COUTINHO, 1976, p. 11). Essa compreensão contrapõe-se, portanto, ao que, de modo geral, pretendem os estudos de história da literatura colonial. Interessa observar que, sempre que os estudiosos da literatura se depararam com uma atitude crítica por parte dos autores coloniais que não os enquadrasse como partidários dos interesses metropolitanos, acabaram por entendê-la como uma manifestação do sentimento nativista.

Não é, assim, na qualidade de opositores da Metrópole e, por conseguinte, de portadores de uma consciência nativista que estamos considerando os autores coloniais. Esta maneira de interpretar somente poderia ocorrer se fosse fundamentada em uma suposta oposição entre metrópole e colônia. Para nós, esta oposição não somente não existia, 
mas seria mesmo inconcebível por parte dos autores coloniais. Quando afirmamos que eles defenderam a colônia, simplesmente estamos destacando 0 fato de que estavam empenhados no processo de constituição da sociedade colonial. Por conseguinte, estamos considerando-os como indivíduos que se encontravam envolvidos na luta pelo desenvolvimento das relações sociais na Colônia. Posicionavam-se, por isso, não contra a Metrópole, mas contra determinados aspectos da antiga sociedade que impediam sua expansão.

Ao considerarmos que esta literatura, por representar novas forças, expressava interesses corporificados na colonização, estamos afirmando que seus autores formularam as questões da perspectiva das relações estabelecidas no Brasil. Em suma, estavam empenhados na organização, expansãoe consolidação da produção colonial.

Se não encontramos nesta literatura qualquer menção que possa ser interpretada como oposição à Metrópole, também não encontramos nela uma ideia que possa ser considerada como partidária da Metrópole, em detrimento da Colônia. Não se observa nesses escritos nem 0 ataque nem a defesa da Metrópole, já que esta não era a questão para aqueles autores. Eles combateram relações e interesses que obstavam a organização, expansão e estabilização da produção na Colônia. Ainda que estes obstáculos se encontrassem radicados no Reino, nem por isso provocaram nessa literatura alguma ideia antimetropolitana.

É o esforço despendido pelas novas forças estabelecidas na Colônia para se expandir e consolidar que elucida os escritos dos séculos XVI e XVII. Ressalte-se que, neste empenho, não constava como objetivo excluir a Metrópole. Antes, a intenção era - e os autores proclamaram isto em mais de uma oportunidade - contar com 0 concurso da Metrópole, ou melhor, da Coroa, para promover 0 desenvolvimento da Colônia. Assim, um dos aspectos mais salientes desta literatura é o propósito de convencer a Coroa a participar efetivamente da colonização, a se interessar mais pelo Brasil e, por conseguinte, a se empenhar mais em sua construção.

Reivindicando uma maior presença da Coroa ou do Estado na Colônia, partiu destes autores a crítica ao abandono do Brasil pelos reis. Gândavo (1980, p. 76) atribuía ao pouco-caso dos portugueses pela nova terra 0 fato de a história do Brasil ter ficado sepultada em silêncio por tanto tempo. Gabriel Soares de Souza (1971, p. 39) também criticou os reis por terem desamparado o Brasil. Nessa época, em que cabia ao Estado um papel decisivo na constituição e expansão das relações sociais, nada 
mais natural que os autores coloniais clamassem por uma atuação ainda mais decidida da Coroa no Brasil.

A maior intervenção da Coroa na Colônia, o cuidado maior da Metrópole com o Brasil, não implicava maior submissão e exploração da Colônia; ao contrário, resultava na sua expansão e fortalecimento. Paradoxalmente, diferentemente do que os historiadores afirmaram, os autores coloniais, ao reivindicarem uma atitude mais "colonialista" por parte da Coroa, estavam, na verdade, defendendo os interesses da Colônia.

Além disso, somente para os historiadores que concebem a relação entre metrópole e colônia como de dominação, imposta de fora para dentro, é que existiria a possibilidade de os povoadores prescindirem do concurso da metrópole, ou melhor, do Estado. De outra forma, fica claro que os colonos não poderiam ter uma existência independente da metrópole. A relação entre a metrópole e a colônia, entre a Coroa e os colonos, não era, pois, externa à existência dos colonos - pelo contrário, era vital para eles.

Coube a Pero de Magalhães Gândavo dar, pela primeira vez de maneira orgânica e sistemática, expressão literária a estas novas forças sociais. Aliás, ele próprio destacou isto na dedicatória do Tratado da Tera do Brasil, chamando a atenção para o caráter pioneiro do seu empreendimento (GÂNDAVO, 1980). Ele havia feito o mesmo no Tratado da Provínia: classificando-o como sumánio da proúnia do Brasil, observou que era "cousa que ategora não imprendeo pessoa alguma" (GÂNDAVO, 1965, p. 55). Escrita na década de 1570, a obra de Gândavo contém questões que, posteriormente, foram retomadas pelos demais autores mencionados.

Consideramos que, em virtude de ser a expressão de interesses ligados à colonização, o conjunto expressivo de obras do século XVI e XVII pode ser denominado escritos cdaniais Tal designação deve-se ao fato de seus autores terem tomado partido das novas forças sociais que estavam se constituindo com a colonização. Escrevendo dessa perspectiva, eles expressaram as exigências de uma nova sociedade ou do novo mundo que estava sendo criado por meio dela.

Com esta denominação, evidentemente, não estamos nos referindo às características que levaram os historiadores a classificar estas obras como cdaniais, isto é, como obras que não tinham uma identidade própria, nacional. Não estamos nos referindo a uma literatura imposta ou a uma mera repetição de modelos oriundos de outras realidades; nem 
estamos nos pautando na ideia de que seus autores seriam partidários dos interesses metropolitanos, fato que os levaria a exprimir uma mentalidade ou uma ideologia colonialista.

Com esta denominação, estamos nos contrapondo à maneira como a historiografia, inclusive a da literatura, caracterizou estes autores. De modo geral, a historiografia classificou-os como aroistas, como autores que, antes de tudo, fizeram uma descrição das condições naturais e sociais da Colônia não como elementos ativos, participantes da história, mas como expectadores da colonização, portadores de certa mentalidade ou ideologia. Em nossa denominação, ao contrário, eles são concebidos como participantes ativos do processo de constituição da sociedade colonial.

A nosso ver, a denominação escritos coloniais possui duas possibilidades. A primeira seria chamar a atenção para o que julgamos ser a questão fundamental destas obras, qual seja, a de que elas expressam os interesses vinculados à organização e expansão das relações sociais na Colônia; a segunda seria permitir englobar sob um mesmo denominador um conjunto de obras formalmente distintas, circunstância que levou a historiografia, frequentemente, a examiná-las em separado (ROD RIGUES, 1979). D esse modo, apesar de o Tratado, de Gândavo, da Históna doBrasil, de frei Vicente do Salvador, e de os Diálogos serem obras distintas quanto à forma e ao gênero, podemos, ao englobá-las sob esta designação, apreender 0 que existe de comum entre elas, o que significa que a denominação vai além de um simples nome e diz respeito a uma maneira de encarar as obras.

Além disso, quando comparamos alguns autores, notamos que, apesar das diferenças quanto à época e quanto às suas próprias condições pessoais, uma preocupação comum perpassa suas obras. Assim, embora seja anterior ao domínio espanhol, Gândavo não se distingue dos autores posteriores a 1580. De fato, ele apresentou a Colônia na mesma perspectiva positiva com que o fez 0 autor anônimo dos Diálogos Gabriel Soares, português, criticou a Coroa pelo abandono da Colônia tal como frei Vicente do Salvador, nascido no Brasil. Tanto Gândavo, gramático e professor, quanto Ambrósio Fernandes Brandão, provável autor dos Diálogos, cristão-novo, feitor de um contratador de dízimos e, posteriormente, senhor de engenho, consideravam os escravos condição essencial para a produção da riqueza. 0 fato de ser um religioso não impediu frei Vicente do Salvador de enfocar a Colônia do mesmo ângulo que Gândavo, um leigo, ou Ambrósio Fernandes, um cristão-novo. Gândavo e Ambrósio Fernandes possuem mais um ponto em comum: 
ambos escreveram sobre a Colônia com os olhos postos no que ocorria em Portugal, nas condições sociais do Reino. Mais do que isso, o autor dos Diálogos foi mais longe: abarcou em suas considerações não apenas a Colônia e o Reino, mas também a América Espanhola e as Índias Orientais, revelando que a questão colonial era bem mais ampla do que nos permite apreender a dicotomia metrópole-colônia.

Podemos afirmar que, ao proceder desta maneira, Gândavo e Ambrósio Fernandes chamam a atenção para algo bastante surpreendente: em Portugal, dadas as condições econômicas e políticas, não existia lugar na produção nem para os pobres nem para os ricos. Os primeiros eram obrigados a pedir de porta em porta; os segundos, forçados a imobilizar pelo menos parte da sua riqueza na forma de tesouro ou aplicá-la em atividades não suficientemente rentáveis, como 0 comércio da Índia. Por isso, Gândavo procurou convencer os pobres a passar para a Colônia e Ambrósio Fernandes fez idêntico apelo aos ricos, principalmente aos cristãos-novos. Verificando alguns pontos em comum entre frei Vicente do Salvador e Ambrósio Fernandes, Capistrano de Abreu (1982, p. 37) aventou a possibilidade de o primeiro ter conhecido o segundo ou, pelo menos, parte de sua obra; no entanto, ainda que possamos descobrir, aqui e ali, outros pontos em comum entre esses autores, o que fundamentalmente os une é o fato de terem se posicionado a favor da colonização.

Evidentemente, a unidade não elimina as diferenças, mas estas, se existem, não advêm do fato de uns serem portugueses de origem e outros, brasileiros de nascimento. Tampouco se deve ao fato de terem escrito obras distintas quanto à forma e ao gênero. São diferenças que se devem à amplitude com que consideraram a colonização. Deste modo, Gândavo e Ambrósio Fernandes destacam-se dos demais por situarem a colonização em uma perspectiva mais ampla, tendo em vista a situação de Portugal. Ambrósio Fernandes foi ainda mais longe: comparou a colonização do Brasil com o comércio da Índia e com a mineração da América Espanhola de maneira a mostrar que a Coroa deveria cuidar antes do Brasil que da Índia (e, talvez, da própria América Espanhola, ainda que não tenha explicitado isso). Gabriel Soares e frei Vicente, ao contrário, trataram exclusivamente do Brasil, reivindicando para este uma maior atenção por parte da Coroa. De qualquer maneira, em todos eles aparece a defesa da colonização.

A Colônia era uma sociedade em formação, cujas circunstâncias históricas particulares reuniam condições favoráveis e desfavoráveis. 0 fato de a antiga sociedade portuguesa se encontrar em dissolução, sem a 
perspectiva de constituição de novas relações sociais, era uma circunstância extremamente favorável. Consideremos esta questão mais de perto.

A expansão marítima, a conquista, a pilhagem da África, 0 comércio com este continente e, principalmente, o comércio com a Índia provocaram a dissolução das antigas relações sociais, como testemunham autores importantes, a exemplo de Sá de Miranda e Gil Vicente. Ao invés de criar novas relações sociais, estes processos proporcionaram aos portugueses meios para viver de forma parasitária. D esta maneira, ricos e pobres não encontravam o caminho da produção, condição para que riqueza e trabalho resultassem em novas relações. Não obstante, se este caminho não existia no Reino, estava sendo construído na Colônia, fato apontado por Gândavo e Ambrósio Fernandes. Por isso, o Reino liberava ricos e pobres para a Colônia, favorecendo a formação e a expansão dessa sociedade.

Por outro lado, o processo não estava isento de percalços. 0 mais importante deles talvez seja o envolvimento da Coroa e de parcela significativa dos portugueses no comércio da Índia. Daí o empenho em combater esse envolvimento e convencer a Coroa, e mesmo os reinóis, a se interessarem mais pela Colônia. Era preciso mostrar que a Colônia era mais rica do que a Índia, que a Colônia proporcionava mais lucro e renda do que o entesouramento e o comércio com a Índia, que Portugal, enfim, corria 0 risco de perder o Brasil, caso continuasse descurando dele, e assim por diante. Ao tomar partido das relações que haviam se estabelecido e estavam se desenvolvendo na Colônia, os autores coloniais se engajaram em uma luta que não estava circunscrita à Colônia e ao Reino, mas tinha por palco o Império português.

Isso leva a inferir que surgimento desta literatura teve sua razão de ser. Como se pode verificar, o estabelecimento e a expansão das novas relações sociais não constituem um processo natural. Segundo Caio Prado (1966), a descoberta do Brasil não conduziu necessariamente à sua ocupação e ao seu povoamento. Nem todos os portugueses estavam interessados nisso. Ao contrário, as nascentes relações sociais enfrentaram dificuldades e obstáculos, como se pode verificar nas cartas que D uarte Coelho (MELLO, 1967) enviou ao rei D. João III, colocando, assim, a necessidade de defendê-las.

Resulta de nossa análise a constatação de que os escritos coloniais não foram fruto da casualidade, nem se caracterizam como obras episódicas e circunstanciais. Correspondem às reivindicações das novas 
forças sociais que se corporificaram com a colonização. Aliás, diga-se de passagem, foi com o propósito consciente de participar desta luta que os autores coloniais escreveram suas obras. Gândavo, Gabriel Soares e Ambrósio Fernandes tinham um objetivo bastante definido e, conscientes do que pretendiam, explicitaram isso em seus escritos.

Conclui-se que suas obras tinham um destino e um uso determinados. Com objetivos bem-definidos, estavam endereçadas a um público específico. De modo geral, dirigiam-se à Coroa, reivindicando uma participação mais efetiva nos destinos da Colônia. Por isso, no estudo dessas obras, não cabe citicar seus autores por terem se dirigido a um público restrito. Afinal, este era seu alvo, era junto dele que buscavam apoio para suas pretensões. Era este público que pretendiam convencer.

Também não consideramos pertinente a observação dos historiadores da literatura, feita em tom de recriminação, de que a produção literária do Brasil era consumida no exterior e raramente retornava à Colônia. Ora, os autores coloniais não se dirigiam ao público da Colônia, ainda que o representassem, mas ao da Metrópole. Gândavo procurava incentivar aqueles que não encontravam meios de se sustentar no Reino, a não ser no parasitismo e na mendicância, a mudar de vida, a vir para a Colônia. Ambrósio Fernandes procurava chamar a atenção da Coroa para o Brasil, propondo que abandonasse o Oriente e se voltasse para onde a riqueza estava verdadeiramente sendo produzida. Pretendia, igualmente, convencer os detentores da riqueza no Reino a passar para 0 Brasil. A observação da historiografia de que as obras literárias eram consumidas na Corte diz mais do que ela supõe. Entender que as obras coloniais deveriam ter outro destino e público significa não compreender 0 que seus autores realmente pretendiam.

0 fato de os escritos coloniais expressarem novos interesses portanto, de não constituírem simples prolongamento da literatura de Portugal - fica evidente ao considerarmos a época em que surgiram. Algumas décadas de colonização já haviam transcorrido quando Gândavo escreveu sua obra. D urante o período anterior, isto é, entre a década de 30, quando ocorreu a colonização sistemática, e a década de 70, quando surgiram os primeiros escritos coloniais, apesar de o processo de colonização já se encontrar em andamento, não temos notícias de obras com características semelhantes às dos escritos coloniais.

Isto demonstra, em primeiro lugar, que estes escritos não eram um simples reflexo, ou seja, um prolongamento da literatura portuguesa. Caso o fossem, encontraríamos obras desta natureza no início da 
colonização, sem que houvesse uma solução de continuidade, quando se sabe que tivemos um interregno entre 0 início da colonização propriamente dita e o surgimento dos primeiros escritos coloniais. Estes escritos são, por conseguinte, algo novo, distinto das obras metropolitanas que os antecederam.

Em segundo lugar, esta circunstância mostra que a colonização não produziu estes escritos naturalmente. Foram necessárias determinadas condições históricas para que esta literatura surgisse. Podemos concluir que se acha vinculada a uma situação nova, criada ou, pelo menos, amadurecida a partir dos anos de 1570.

A formulação de que as forças sociais criadas com a colonização somente encontraram sua expressão nos textos surgidos a partir de 1570 pode ser comprovada por meio da análise da literatura produzida pelos primeiros jesuítas - cartas, informações, relatórios. Esta literatura não estava totalmente identificada com os novos interesses. Mais do que isto, de modo geral, a literatura jesuítica opôs-se a eles, indicando que a religião, pelo menos nos primórdios da colonização, não estava em completa sintonia com as novas forças sociais.

O padre Manuel da Nóbrega, por exemplo, condenou os colonos por terem deixado de se mover pela religião, optando pelo provita Segundo este jesuíta, eles colocavam em primeiro plano o provito e seus interesses, antes mesmo do serviço do Rei ou da religião: "Os homens comumente não têm respeito senão ao seu proveito e próprio interesse e um pouco ao serviço de El-Rei: e para Nosso Senhor não há respeito algum" (1940, p. 49).

A colonização promoveu uma verdadeira subversão nos valores do mundo feudal, fazendo com que o proveto fosse colocado acima de qualquer outro valor. Ainda presos ao antigo mundo, os jesuítas condenavam a cobiça, ao contrário dos autores coloniais, que, expressando os novos interesses, faziam do provito a ótica com que examinavam as questões da sua época.

Em carta que escreveu a Tomé de Sousa, em 1559 - depois, portanto, que este deixara o cargo de governador do Brasil e retornara a Portugal -, Nóbrega mostrou que religião e provito estavam em campos opostos: “(...) porque esta gente do Brasil não tem mais conta que com seus Engenhos e ter fazenda, aynda que seja com perdição das almas de todo 0 mundo" (LEITE, III, 1954, p. 98). Também o padre Antonio Blásquez, em carta de 1558, dirigida ao padre Diogo Laynes, colocou em oposição o interesse individual e a religião: "25. Otro estorvo mayor que 
éste tenemos, y es que como la gente desta tierra ni busca ni pretende la gloria de Dios, ni el bien universal sino lo suyo de cada uno particular, todos son en estorvar esta obra y esfriar la voluntad y fervor que el Governador amuestra" (LEITE, II, 1954, p. 440).

Muitos aspectos que representavam a nova época foram objeto de crítica por parte dos jesuítas. Compare-se, por exemplo, o modo como os jesuítas e os escritores coloniais encararam o proveito, elemento propulsor da colonização, e a escravidão, meio de alcançar seu desenvolvimento. Enquanto os escritores coloniais consideravam a escravidão essencial para a Colônia (PEREIRA, 1986, p. 17), os jesuítas a condenavam, julgando-a uma instituição desnecessária. Os primeiros afirmavam que os escravos eram o meio de os portugueses se sustentarem na terra, conforme expressão bastante utilizada por eles: sem os escravos não era possível viver no Brasil (GÂNDAVO, 1980, p. 42). Os jesuítas, por seu turno, criticavam os colonos por querer escravizar os índios. Nóbrega, por exemplo, condenou os portugueses por quererem viver do trabalho dos escravos: "Os homens que para aqui vêm, não acham outro modo senão viver do trabalho dos escravos" (Apud GOULART, 1975, p. 34).

Contrário à escravidão, o Irmão António Blásquez, em carta de 1558, dirigida ao padre Diogo Laynes, criticou os colonos por se preocuparem mais com o proveito do que com a salvação das almas dos índios: “(...) comúnmente no quieren más delhos que servirse de sus cuerpos como de cavalhos o otras bestias" (LEITE, v. II, 1954, p. 433). Anchieta, igualmente, em carta de 1561, condenou os portugueses por quererem mais os serviços dos índios do que a salvação de suas almas, motivo que os levava a espargir os índios por suas fazendas (ANCHIETA, 1988, p. 179). Para os jesuítas, os portugueses que, movidos pela cobiça e pelo interesse, possuíam índios cativos encontravam-se em pecado, com suas consciências carregadas (LEITE, I, 1954, p. 202).

Percebe-se, desse modo, que os jesuítas das primeiras décadas pretendiam que a colonização fosse subordinada à religião. Por isso, afirmavam constantemente que o objetivo principal da colonização era a propagação da fé, devendo o provitoficar em segundo plano.

Ao contrário dos jesuítas, os autores leigos do período colonial, ainda que não tivessem estabelecido uma oposição sistemática entre colonização e religião, subordinaram a segunda aos propósitos da obtenção do proveita Para eles, comumente, religião e colonização, religião e provito, religião e escravidão concorriam para um mesmo objetivo. 
Foi preciso que transcorressem algumas décadas e surgissem fatos novos para que se manifestasse uma literatura explicitamente identificada com a colonização, que tivesse o objetivo de expressar os interesses corporificados na colonização. A creditamos que o amadurecimento da colonização e a consolidação dos seus interesses tenham sido fatores para o surgimento desta literatura.

É importante, ainda, observar que, apesar de não encontrarmos, no período anterior a 1570, nenhuma obra com características dos escritos coloniais, esse fato não implica que os interesses coloniais não existissem. Ao contrário, eles se manifestaram com bastante vigor em determinadas ocasiões, se bem que não na forma literária. Um dos exemplos mais expressivos desta manifestação são os conflitos ocorridos nos primeiros tempos dos núcleos coloniais entre os colonos propriamente ditos e os mercadores que faziam o escambo do pau-brasil com os indígenas. Nestes conflitos fica patente não só o estabelecimento de novas forças sociais, cujo fundamento era a produção, mas também a não coincidência entre os interesses dessas novas forças e os dos setores vinculados à coleta e comércio do pau-brasil.

Estes conflitos encontram-se registrados nas cinco cartas que restaram das enviadas por Duarte Coelho, donatário da capitania de Pernambuco, ao rei de Portugal, D. João III (MELLO; ALBUQUERQUE, 1967; MENDES, 1986-1987). O fato de estes conflitos terem eclodido com mais intensidade nessa capitania confirma nossa asserção de que a colonização criou um novo tipo de interesse: 0 vinculado à obtenção do provito por meio da produção sistemática. Mais importante ainda, confirma que a colonização estava em oposição às forças vinculadas à prática mercantil, cujo ponto culminante foi 0 comércio com a Índia.

Neste sentido, a fundação de feitorias e a obtenção do pau-brasil por meio do escambo não constituem a primeira etapa da colonização, mas os últimos momentos da forma mercantil do capital. A organização da produção, mais do que o trânsito da circulação para a produção sob os auspícios do capital mercantil, como pretende a historiografia, significa a emergência de uma nova forma de capital: 0 capital produtivo. Consideremos esta questão.

Em carta de 1546, Duarte Coelho escreveu que havia "muitos inconvenientes e estorvos para ir a cousa em crescimento e aumento". Dentre estes inconverientes e estorvos que impediam o cresimento e aumento da Nova Lusitânia destaca a extração do pau-brasil - ou, segundo a 
expressão que aparece em suas cartas, o fazer-se pau brasil. Segundo 0 donatário, a forma como os mercadores obtinham licença para a coleta e se conduziam em relação aos índios prejudicava os que haviam investido sua fazenda1 na organização da produção:

Porque, por fazerem seu Brasil, importunam tanto os índios e prometem-lhes tanta cousa fora da ordem, que metem a terra em desordem da ordem em que eu a tenho posto; e se lhes dão alguma cousa do que lhes prometem, deitam a perder 0 concerto e ordem que eu tinha posto para o que convém ao trabalho deste Brasil, quando Vossa Alteza se quiser servir dele. Porque não basta, Senhor, dar-lhes as ferramentas, como está em costume, mas, por induzirem os índios a fazer o Brasil, dãolhes contas da Bahia e carapuças de pena e roupas de cores que homem aqui não pode alcançar para seu vestir, e, o que é pior, espadas e espingardas, (...). Porque afirmo a Vossa Alteza que de três anos para cá se perverteu este fazer de Brasil, que põe em muita confusão a terra, e a mim dá grande trabalho e fadiga em acudir a tantos desconcertos e remediar desacertos. A té nos estorva este fazer de Brasil o fazermos nossa fazenda, em especial os engenhos, porque quando estavam os índios famintos e desejosos de ferramentas, pelo que lhes dávamos nos vinham a vender mantimentos de que temos assaz necessidade, e, como estão fartos de ferramentas, fazem-se piores do que são e alvoroçam-se e ensoberbecem-se e revoltam-se (MELLO; ALBUQ UERQUE, 1967, p. 88).

Fica evidente que não só a coleta do pau-brasil e a produção do açúcar eram atividades incompatíveis, mas também que a atividade dos mercadores resultava na desorganização da produção, já que criava nos indígenas necessidades que os colonos não tinham condições de satisfazer.

Além disso, a atitude dos mercadores fazia os índios se revoltar, fato que obrigava os colonos a gastar sua fazenda com munições. Assim, ao dificultar aos colonos fazerem seus provitos, comprometia o próprio estabelecimento colonial. Segundo o próprio Duarte Coelho, os portugueses tinham vindo para 0 Brasil com 0 objetivo de viver espalhados em suas terras, levantando engenhos e plantações e fazendo seus provitos Os portugueses não tinham vindo para a colônia para ficar entrincheirados em fortalezas, como viviam no passado os senhores

1 Segundo Bluteau, fazenda significa riquezas, dinheiro, cabedais, bens de raiz, terras, quintas (BLUTEA U, v. 4, 1712, p. 48). 
feudais ou os portugueses na Índia: "As fazendas, em especial os engenhos, estão espalhados e não juntos, e os que vêm a fazer estes engenhos não vêm como homens poderosos para resistir, mas para fazerem seus proveitos e para eu os haver de amparar e defender como cada dia faço" (MELLO; ALBUQUERQUE, 1967, p. 88).

Afirmar que não podiam fazer sas provitos é o mesmo que afirmar que as relações sociais que se reproduziam por meio do lucro estavam encontrando obstáculos à sua existência. Se os que faziam o pau-brasil estavam criando dificuldades para 0 estabelecimento da produção agrícola, então existia uma incompatibilidade entre estas duas atividades. A coleta do pau-brasil, que representava a forma mercantil do capital, dificultava a fabricação do açúcar, forma assumida pelo capital produtivo. Assim, não tem fundamento a afirmação da historiografia de que 0 período colonial se caracterizou pela hegemonia do capital mercantil. Este estava, de fato, sendo suplantado e contestado pelo capital produtivo.

Como solução para o problema, Duarte Coelho requeria que se protegesse a produção (isto é, os colonos) por meio de uma provisão que impedisse, pelo espaço de dez ou doze anos, a coleta do pau-brasil a menos de vinte léguas de todas as povoações existentes em Nova Lusitânia. Este problema, no entanto, não era de fácil solução: a própria Coroa portuguesa tinha interesses ligados à coleta do pau-brasil. Era uma das suas fontes de renda. Com isso, ao menos parcialmente, o Estado português se inclinava em favor dos armadores; entretanto, na medida em que a tera ia emaumento, o donatário de Pernambuco, criticando o Rei por ter em tão paro as terras do Brasil, achava-se em condições de exigir da Coroa uma definição precisa sobre 0 assunto.

Entraves dessa natureza, além de outros, como os interesses vinculados ao comércio da Índia, que levavam a Coroa a desarar do Brasil, mostram o solo onde brotaram os escritos coloniais.

\section{CONCLUSÃO}

Como pudemos alertar, o estudo dos escritos coloniais mostra fatos interessantes. Autores que a historiografia considerou comprometidos com a Metrópole, taxando-os de porta-vozes dos interesses metropolitanos, expressaram os anseios e os interesses dos colonos. Sem ver nisso qualquer contradição, ao defender a Colônia, eles exigiam uma presença mais efetiva da Coroa no Brasil, como fica nítido 
em Gabriel Soares de Sousa. Assim, aspirações que a historiografia interpretou como as primeiras manifestações nativistas depositavam no Estado metropolitano a esperança de promover o aumento da Colônia. Mais ainda, amigos do Brasil, como foram definidos pelos historiadores da literatura, estes autores reivindicavam uma participação mais efetiva da Metrópole na vida da Colônia.

Isso pareceria uma situação paradoxal, uma contradição, mas quando analisamos esta literatura fora da oposição entre metrópole e colônia, considerando-as polos opostos de uma relação, podemos solucionar o aparente paradoxo. Com efeito, é preciso considerar que metrópole e colônia faziam parte de um todo, do Império português, e que a colonização constituiu um desdobramento dos processos por que passava o Reino. Sob este aspecto, a organização da produção na Colônia atendeu, de um lado, às novas exigências que então se colocavam, a saber, a organização da produção sob o comando do capital, ou cabedal, segundo formulação de Antonil (2007), e de outro, que as condições do Reino não davam ensejo para esta organização, levando os portugueses, movidos pela ânsia de procito a se transladarem para outras regiões, onde este propósito tinha melhores condições de ser alcançado. Sob este aspecto, os novos interesses foram representados por meio da literatura em seus diversos momentos e de uma forma determinada. Em fins do século XVI e início do XVII, a forma de representação foram os escritos coloniais.

\section{REFEREN NIAS}

ABD ALA JR., Benjamin; CAMPEDELLI, Samira Youssef. Tempos da literatura brasilèra. São Paulo: Ática, 1985.

ABREU, Capistrano. Nota preliminar. In: VICENTE DO SALVADOR, frei. Históna do Brasil (1500-1627). 7ạ ed. Belo Horizonte/ São Paulo: Itatiaia/ USP, 1982.

ANCHIETA, José de. Cartas: infomaçães, fragmentos histónicos esermões Belo Horizonte/ São Paulo: Itatiaia/ USP, 1988.

ANT O NIL, André João. Cultura equilênia do Brasil par suas drogas eminas São Paulo: USP, 2007.

BLUTEAU, D. Raphael. V oabulario partuguez elatima 8 v. Coimbra: Real Collegio das Artes da Companhia de Jesus, 1712.

BO SI, Alfredo. Históna conisa da literatura brasileira. São Paulo: Cultrix, 1970. 
CAND ID O , Antonio. Letras e ideias no Brasil colonial. In: HOLAND A, Sérgio Buarque de (dir.). Histónia Geral da Civilização Brasileira. t. I, v. 2. 5ạ ed. São Paulo: D ifel, 1982.

CASTELlO, José Aderaldo. A literatura brasilera. I. Manifestações literárias da época colonial (1500-1808/ 1836). 3ae ed. São Paulo: Cultrix, 1969.

COUTINHO, Afrânio. Conceito de literatura brasileira Rio de Janeiro: Pallas/ INL/ MEC, 1976.

GÂNDAVO, Pero de Magalhães. Tratado da Proíndia do Brasil. Rio de Janeiro: Instituto Nacional do Livro/ Ministério da Educação e Cultura, 1965.

GÂNDAVO, Pero de Magalhães. Tratado da Tera do Brasil: História da Província de Santa Cruz. Belo Horizonte/ São Paulo: Itatiaia/ USP, 1980.

GO ULART, Maurício. A escravidão africama no Brasil. 3ạ ed. São Paulo: Alfa-O mega, 1975.

KOSHIBA, Luiz. A hanra e a cobiça Estudo sobre a origem da colonização. 2 v. São Paulo, 1988. T ese (D outorado em História) - USP.

LEITE, Serafim. Cartas dos priminos jesútas no Brasil. 3 v. São Paulo: Comissão do IV Centenário da Cidade de São Paulo, 1954.

MELLO, José Antonio Gonsalves; ALBUQUERQUE, Cleonir Xavier (eds.). Cartas de Duarte Codho a El-Re. Recife: Imprensa Universitária, 1967.

MENDES, Claudinei Magno Magre. As cartas de Duarte Coelho a El-Rei D. João III. O conflito entre o capital produtivo e o capital mercantil. Históna. São Paulo, v. 5-6, 1986-1987.

NÓ BREGA, Manuel. Carta ao P. Luiz Gonçalves da Câmara. De S. Vicente. 15 Jun. 1553. In: LEITE, Serafim. Novas cartas jesúticas (de Nóbrega a Vieira). São Paulo: Nacional, 1940.

PEREIRA, Lupércio Antônio. Limites histónicos do pensamento abdicionista. Uma contribuição ao estudo do gradualismo adotado na abolição da escravidão no Brasil. Assis, 1986. Dissertação (Mestrado em História) Unesp.

PRAD O JR., Caio. Fommação do Brasil contemparânea. 17ạ ed. São Paulo: Brasiliense, 1981.

PRADO JR., Caio. Evdução política do Brasil e atros estudos $5^{\underline{a}}$ ed. São Paulo: Brasiliense, 1966. 
RODRIGUES, José Honório. Histónia da Histónia do Brasil. 2ª ed. São Paulo: Nacional, 1979.

SO USA, G abriel Soares de. Tratado descritivo do Brasil em 1587. 4ํe ed. São Paulo: Nacional/ USP, 1971.

TUCK, Richard. História do pensamento político. In: BURKE, Peter (org.). A escrita da histónia: novas perspectivas. São Paulo: Edunesp, 1992.

VICENTE DO SALVADOR, frei. Históiia do Brasil (1500-1627). 7a ed. Belo Horizonte/ São Paulo: Itatiaia/ USP, 1982. 